Revista Iberoamericana, Vol. LXIX, Núm. 203, Abril-Junio 2003, 425-430

\title{
ESTUDIOS CULTURALES, ACCIÓN INTELECTUAL Y RECUPERACIÓN DE LO POLÍTICO
}

\author{
POR \\ Mabel Moraña \\ University of Pittsburgh
}

Resulta casi imposible no ver en la reciente clausura del Departamento de Estudios Culturales de la Universidad de Birmingham un alegórico signo de los tiempos que corren. Ese espacio académico, que fuera cuna de los Cultural Studies a mediados de los años sesenta, se cierra "en su forma presente”, según la información provista por el Guardian el 27 de junio de 2002, derivando sus componentes de sociología, comunicación, cultura y sociedad hacia otros institutos de estudios sociales aplicados. ${ }^{1}$ La medida responde, al parecer, a la baja clasificación que el departamento obtuviera, pese a su excelencia educativa, en los rankings anuales que estiman sobre todo el nivel de investigación realizada por los miembros del departamento en cuestión. Los rigores y restricciones de la institucionalización, que en tantos otros planos habría atentado ya, según muchos practicantes de los cultural studies, contra el espíritu mismo de esta orientación en la que convergen esfuerzos renovadores de distintas vertientes de la izquierda académica, pone punto si no final al menos suspensivo a las casi cuatro décadas de desarrollo institucional, en el ámbito británico, de esta modalidad de análisis e interpretación cultural que resiste aún el ser calificada como escuela, método o disciplina. El futuro de los cultural studies británicos enfrenta ahora, por lo menos en Birmingham, la realidad de una desterritorialización académica que exigirá nuevas formas de supervivencia y diseminación del conocimiento, nuevas estrategias y articulaciones transdisciplinarias -interdepartamentales_, nuevas políticas educativas dentro del campo de poder institucional.

No es la tarea de difusión académica ni el expansionismo transnacional de la buena nueva de los estudios culturales lo que estaría fallando, según algunos —y no sólo en el caso británico — sino quizá, podría especularse, su grado de exploración y productividad epistemológica, su rendimiento concreto y profundo en la aplicación misma de los principios del análisis, su cualidad revulsiva (o habría que decir, simplemente, política o —usando un arcaísmo- revolucionaria?). En otros contextos —en Estados Unidos,

\footnotetext{
${ }^{1}$ Según Polly Curtis, quien firma la nota en la que el Guardian da cuenta del cierre del Departamento de Estudios Culturales, esta unidad académica se encontraría en proceso de reestructuración. Ante la puerta cerrada alguien habría colocado un papel en que se lee: "This department has been cancelled. Nothing else matters.” Agradezco a Carlos Jáuregui la referencia a este artículo.
} 
Australia, América Latina — variantes de la versión británica continúan desarrollándose con un vitalismo en que la cantidad abrumadora de aportes parece exceder en mucho a su profundidad e innovación . En muchos casos, podría afirmarse que algunos de los mejores artículos producidos en el campo de los estudios culturales son aquellos en los que esa práctica reflexiona, en un gesto pesadamente autoreferencial, sobre sí misma: sus fundamentos epistemológicos, sus principios anti, pos o transdisciplinarios, su carencia de restricciones y definiciones metodológicas, su genealogía, necesidad históricoideológica y funcionalidad académica e intelectual.

En un texto de 1997 Néstor García Canclini caracterizaba ya entonces el estado de los estudios culturales en el campo de las Humanidades con un término usado para describir crisis económicas: estanflación (“estancamiento con inflación”), indicando que

En los últimos años se multiplican los congresos, libros y revistas dedicados a estudios culturales, pero el torrente de artículos y ponencias casi nunca ofrece más audacias que ejercicios de aplicación de las preguntas habituales de un poeta del siglo xvII, un texto ajeno al canon o un movimiento de resistencia marginal que aún no habían sido reorganizados bajo este estilo indagatorio (45)

Citaba, sin embargo, algunos logros que habrían permitido, a su juicio, en el ámbito estadounidense, "pensar de otro modo los vínculos con la cultura y la sociedad” (46) modificando sustancialmente el análisis de los discursos dentro del espacio de las Humanidades, campo que acusó más ampliamente incluso que el de las ciencias sociales, el impacto renovador de los estudios culturales. ${ }^{2} \mathrm{Y}$ resaltaba la importancia de esos estudios sobre todo para el asedio de los problemas vinculados con el multiculturalismo tanto dentro de América Latina como en las relaciones de contacto y flujo cultural que ésta mantiene con Estados Unidos.

En todo caso, es obvio que a pesar de las múltiples debilidades que muestra hoy en día la práctica culturalista, su rendimiento teórico frente a problemas como los que presenta la globalización, su propuesta ya no inter sino decididamente transdisciplinaria, su trabajo de erosión del proyecto ilustrado y modernizador, su crítica de las identidades entendidas ontológicamente como esencias ahistóricas y administradas a partir de las ideologías e instituciones dominantes, para citar sólo algunos de los planos a que se aboca el análisis cultural, resulta insoslayable.

Quizá la gran popularidad alcanzada por los estudios culturales — popularidad que en gran medida contribuye a que el balance resulte a veces desalentador- haya sido el signo más claro de que la apertura de las Humanidades hacia la orientación originada en Birmingham responde no solamente a un agotamiento de los recursos disciplinarios ante nuevos desafíos presentados por la cultura, entendida ahora más que nunca, en tiempos de globalización, como un campo de poder, sino asimismo a una transformación radical del

\footnotetext{
${ }^{2}$ En el caso de América Latina, libros como La jaula de la melancolía (1987) de Roger Bartra y Escenas de la vida posmoderna (1994) de Beatriz Sarlo, darían ejemplo, según García Canclini, de estudios fecundos en los que se analizan "las injusticias de la representación" dentro del marco de una crítica que resalta "la necesaria reforma del Estado-nación”.
} 
espacio social transnacionalizado. Esta transformación requeriría instrumentos inéditos, o al menos innovadoramente combinados, de análisis e interpretación. Al hablar de esas transformaciones radicales me refiero no solamente a los cambios económicos profundos del tardocapitalismo y el diseño global empresarial, sino asimismo a la cancelación de muchas de las vías que permitieron durante la vigencia plena de los proyectos modernizadores organizar respuestas orgánicas a estrategias de poder e ideologías hegemónicas a diversos niveles. Abarco, asimismo, las modificaciones profundas del sistema educativo y su articulación cada vez más estrecha al mercado cultural, desde los niveles más básicos de instrucción hasta las capacitaciones técnico-profesionales y el desarrollo de espacios de competencia (expertise) que superan en mucho lo que podía ser abarcado desde las formas más establecidas de las ciencias sociales, la hermenéutica, la semiótica y las ciencias políticas.

La caída del socialismo real, el resurgimiento de fundamentalismos religiosos, políticos y epistémicos, el vaciamiento acelerado del Estado y las instituciones políticas y sociales mediadoras entre cúpula política y sociedad civil, la proliferación de discursos y de espacios de intercambio intelectual reales y virtuales, el incremento de las comunicaciones a partir de las cuales la cultura de masas atraviesa, coloniza y fermenta a la "alta” cultura, la pérdida de centralidad del discurso letrado ante las formas más agresivas y accesibles del mensaje audiovisual, para citar sólo algunos de los cambios más visibles en la sociedad actual, producen rupturas muy profundas en los fundamentos mismos del saber occidental, técnico y humanístico, y multiplican las preguntas que se hacen al campo cultural como lugar privilegiado de intercambios, procesos y rearticulaciones ideológicas. El surgimiento de nuevas hegemonías en el contexto de la globalidad y la reactivación, ahora sustancialmente modificada, de las relaciones Norte/Sur en el caso de América Latina, son niveles que requieren un trabajo crítico e interpretativo que no puede efectuarse desde espacios intelectuales marcados por dinámicas sociales y políticas que delineaban, en el siglo pasado, horizontes de acción y reflexión muy diversos a los actuales. Ante el descaecimiento de políticas partidistas y movimientos de liberación, ante el debilitamiento creciente de las culturas nacionales como espacios de identidades fijas, fuertemente territorializadas y administradas a partir del Estado, ante la reproducibilidad constante de discursos, mensajes, informaciones y productos culturales, y ante el surgimiento de movimientos sociales que se expresan a través de agendas híbridas, de fuerte capacidad desestabilizadora para el Estado liberal y sus instituciones, los parámetros conceptuales a partir de los cuales se efectúa el análisis de discursos y la interpretación de prácticas sociales requiere una renovación sustancial de sus bases filosóficas, éticas y políticas.

En este sentido, los estudios culturales parecieron ofrecer una plataforma de acción intelectual, un espacio de convergencia y debate que enfocaba prioritariamente, como espacio de análisis, los campos de fuerza que tensan y atraviesan el espacio dialógico de la cultura y los actores, agendas y estrategias que los ponen en funcionamiento. Para lograrlo, gran parte de los esfuerzos teóricos se orientó hacia una crítica profunda de la modernidad como proyecto hegemónico de las burguesías nacionales, que trasladaron al campo de la cultura las luchas por la monopolización de los discursos que ordenaban el mapa cultural y social a todos los niveles: político, educativo, histórico, recreativo, 
religioso, artístico, comunicacional, etc. La noción de diferencia, que plantea en diversos niveles la contracara de los discursos identitarios, nacionalistas y liberales, pasa así a un primer plano, permitiendo dar cuenta de la diversidad y conflictividad (heterogeneidad, hibridez) de formaciones sociales que no responden a los principios de conciliación y consenso que auspiciaran los proyectos republicanos desde la Independencia, sino que manifiestan, en su constitución y funcionamiento, la tensión irresuelta derivada de su condición neocolonial. El rebasamiento de los modelos que dieron base a la historiografía liberal no sólo pone en abismo las bases conceptuales de las disciplinas que se consolidan con el positivismo, sino que al mismo tiempo potencia el campo cultural como el lugar en el que se dirimen las luchas representacionales entre fuerzas políticas y sociales que se asientan no ya en raíces de territorialidad inmediata y administrada por los proyectos nacionales, sino en dinámicas reales y virtuales que rebasan la noción misma de realidad (la temporalidad, la espacialidad) promovida por la razón ilustrada y por la lógica modernizadora. La subjetividad, a nivel individual y colectivo, sufre transformaciones que alteran los procesos de (re)conocimiento, interacción y proyección social, al ser interpelada desde lugares no previstos de producción y reproducción simbólica. Los sujetos que plantean programas alternativos antihegemónicos, activados como actores sociales ya no articulados desde las plataformas de la izquierda, el sindicato, el partido, etc., elaboran agendas sectoriales que permiten movilizaciones acotadas, más reivindicativas que políticas (para utilizar una distinción setentista que va cayendo en desuso) que responden a problemáticas puntuales, que desplazan lo político a lo social, lo ideológico a lo cultural, creando flujos e intercambios entre niveles que la modernidad había creado el hábito de separar asépticamente. Lo político aparece en muchos casos apenas como un excedente (un residuo, un resabio, un epifenómeno) de lo cultural y no como la trama misma de sus interacciones.

En este panorama, los estudios culturales se mueven no sólo efectuando un diagnóstico —analítico e interpretativo — de lo social, sino como un síntoma, ellos mismos, del “nuevo orden” político, económico y cultural globalizado. El problema es, entonces, cómo recapturar lo político, desde qué plataformas, con qué propuestas, a partir de qué bases filosóficas, éticas, conceptuales, y de acuerdo a qué objetivos. Cómo relocalizar, entonces, el lugar de la cultura, para evitar su reificación. Sin que esto haga necesaria una base consensual ni una recuperación de los universales que marcaron los proyectos de la modernidad, es evidente que el problema llama a una reagrupación, aunque sea estratégica, del pensamiento crítico y de las políticas alternativas a la globalización, y a una redefinición del lugar del intelectual en las escenas locales, regionales, nacionales y transnacionales.

En este sentido, los estudios culturales han ayudado, por un lado, a vislumbrar plataformas posibles para la reubicación del intelectual, tanto a nivel académico como en las instancias de actuación pública e independiente que abrirían lugares inéditos de acción y reflexión, desde las funciones educativas a las posiciones vinculadas a la administración del mercado de los bienes simbólicos, desde los puestos de trabajo de las ONGs hasta las capacitaciones tecnológicas avanzadas, desde el advisement en el terreno de las políticas culturales alternativas hasta las cercanías más peligrosas de asesoramiento al poder estatal 
y sus instituciones orgánicas. La tarea intelectual se modifica, complica y combina, de maneras inéditas, con otras funciones o “misiones” menos "pedagógicas” y muy diversamente "hermenéuticas", a veces de corte administrativo, empresarial o tecnocrático. ${ }^{3}$

Es evidente, en todo caso, que la función del intelectual moderno como vocero del nacionalismo o como humanista/político programáticamente "situado", articulado o contrapuesto al Estado y sus instituciones, va dejando lugar - y esto varía según los contextos culturales - al intelectual como figura de negociación o mediación que existe en los intersticios entre disciplinas, espacios de poder, ideologías, territorios, cuyo valor se establece no sólo en gran parte en la medida en que los productos — saberes - que es capaz de colocar en el mercado de bienes simbólicos capturan las necesidades y la imaginación de un mercado omnipotente y omnipresente, local y al mismo tiempo globalizado. ${ }^{4}$

Por otro lado, los estudios culturales impulsaron también otras modalidades de acción intelectual que, marcadas por la voluntad de conquistar una "vanguardia” políticoideológico-cultural ante el vacío de propuestas antihegemónicas orgánicas, convirtieron la reflexión sobre la diferencia en una escena de autoreconocimiento, en la que el intelectual explora nuevas formas posibles para afirmar su centralidad y mesianismo frente a una otredad que sirve primariamente como confirmación del yo que piensa. En el artículo antes citado, García Canclini, llama la atención sobre la necesidad de "pasar del énfasis sobre la identidad a una política de reconocimiento" y sobre la conveniencia de distinguir, entonces, en la elaboración de políticas antihegemónicas, "entre conocimiento, acción y actuación; o sea entre ciencia, política y teatro":

Un conocimiento descentrado de la propia perspectiva, que no quede subordinado a las posibilidades de actuar transformadoramente o de dramatizar la propia posición en los conflictos, puede ayudar a comprender mejor las múltiples perspectivas en cuya interacción se forma cada estructura intercultural. Los estudios culturales, entendidos como estudios científicos, puede ser ese modo de renunciar a la parcialidad del propio punto de vista para reivindicarlo como sujeto no delirante de la acción política. (60)

Creo que la tentación por reafirmar el protagonismo intelectual desde posiciones de centralidad y privilegio atenta principalmente contra una verdadera recuperación de lo político, entendido ya no sólo como el teatro en que se escenifican y dirimen las luchas de poder a nivel simbólico y representacional, sino como un espacio participativo y creativo de resistencia y movilización social.

En esta economía de acciones y principios, plataformas y parámetros conceptuales, los estudios culturales siguen constituyendo una arena importante y al mismo tiempo movediza e inestable de intercambio y elaboración, cuyo principal desafío quizá sea el de resistir los peligros de la cooptación institucional y aprender a desarrollar estrategias ya no sólo de supervivencia sino de autocuestionamiento y control de calidad de sus propios

\footnotetext{
${ }^{3}$ Para un análisis sumario de los cambios sociales y la función interpretativa de los cultural studies ver Yúdice, "Estudios culturales...”.

${ }^{4}$ Sobre la modificación de la función intelectual en el contexto de la globalidad, en el caso particular de las revistas, ver Moraña.
} 
productos simbólicos, teóricos e ideológicos. Hasta ahora, el desmontaje de la ilustración y la modernidad ha sido mucho más efectivo que el del neoliberalismo y la globalización, y la crítica a la institucionalidad académica, la restricción disciplinaria y el exclusivismo humanístico mucho más productivos que las estrategias para reemplazarlos con proyectos verdaderamente democráticos en el interior de los cuales sobrevivan la independencia intelectual y las políticas de inclusión tanto como las posibilidades de conflicto, intercambio y pluralización. Si bien ya es evidente que los estudios culturales han triunfado en la tarea de colonizar el estatuto de las humanidades y las ciencias sociales, queda aún por probarse su verdadera capacidad de intervención y de interpelación política. Esto permitiría saber, una vez desmontada la modernidad, qué hacer con sus fantasmas.

BiBLIOGRAFÍA

Curtis, Polly. “Birmingham’ Cultural Studies Department Given the Chop”. http:// education.guardian.co.uk (7/16/2002)

García Canclini, Néstor. “El malestar en los estudios culturales”. Fractal 6 (otoño 1997): 45-60.

Moraña, Mabel. “Revistas culturales y mediación letrada en América Latina”. (en prensa). Yúdice, George. “Estudios culturales y sociedad civil”. Revista de Crítica Cultural 8 (Mayo 1994): 43-53.

"La reconfiguración de políticas culturales y mercados culturales en los noventa y siglo XXI en América Latina”. Número especial: Mercado, editoriales y difusión de discursos culturales en América Latina. María Julia Daroqui y Eleonora Cróquer, eds. Revista Iberoamericana LXVII/197 (Octubre-Diciembre 2001): 639-60. 